\title{
A gender-medicine post hoc analysis (MetaGeM) project to test sex differences in previous observational studies in different diseases: methodology
}

\author{
This article was published in the following Dove Press journal: \\ Open Access Journal of Clinical Trials \\ 13 October 2014 \\ Number of times this article has been viewed
}

\section{Delia Colombo' \\ Gilberto Bellia' \\ Donatella Vassellatti' \\ Emanuela Zagni' \\ Simona Sgarbi ${ }^{2}$ \\ Sara Rizzoli}

'Novartis Farma, Origgio, ${ }^{2}$ MediData, Modena, Italy

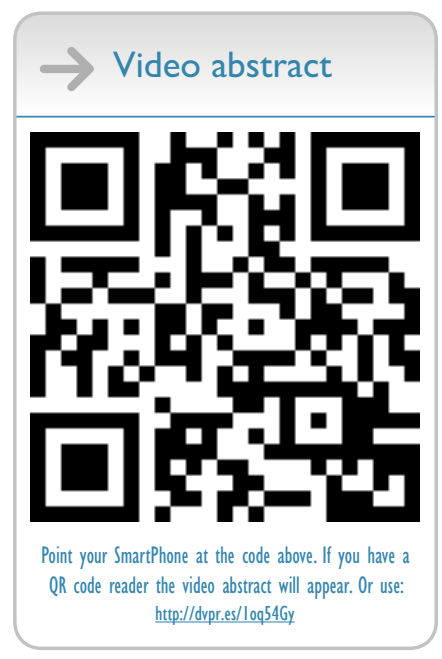

Correspondence: Gilberto Bellia Novartis Farma, I Largo Umberto Boccioni, VA 21040, Italy Email gilberto.bellia@novartis.com

\begin{abstract}
Only recently has medical research begun to understand the importance of taking sex into account, recognizing that symptoms and responses to medical treatment may be very different between males and females. However, the analyses provided by the pharmaceutical industry to regulatory authorities often do not present safety and efficacy data by sex. Novartis has started a gender-medicine project called MetaGeM, which includes nine observational studies sponsored by Novartis Farma, Italy; conducted in Italy between 2002 and 2013 in a range of different clinical areas. The MetaGeM project aims to analyze and describe by means of post hoc analyses and meta-analyses, clinical outcomes, therapeutic approaches, and safety data of these studies, by sex: PSYCHAE; GENDER ATTENTION in psoriasis; Synergy in psoriatic arthritis; ICEBERG in HBsAg carriers; SURF and CETRA in liver- and renal transplanted patients, respectively; DEEP in Parkinson's disease; and EVOLUTION and AXEPT in Alzheimer's disease. The present paper describes the methodology of the MetaGeM project.
\end{abstract}

Keywords: gender-medicine, MetaGeM project, methodology

\section{Background}

Sex is the property or quality by which organisms are classified as female or male on the basis of their reproductive organs and functions, while gender is expressed in terms of masculinity and femininity. It is how people perceive themselves and how they expect others to behave, and is largely culturally determined. ${ }^{1}$ Sex-specific medicine is the study of how diseases differ between men and women in terms of prevention, clinical signs, therapeutic approach, prognosis, and psychological and social impact. It has been a neglected dimension of medicine for a long time. However, clinical data suggest that men and women exhibit differences regarding pharmacology and drug toxicity, as well as the epidemiology and progression of certain diseases, including autoimmune and liver diseases. ${ }^{2}$

Males and females differ in their responses to drug treatment, and such differences can be critical in response to therapy. This is the result of physiological differences, such as body weight, surface area, total body water, and extracellular and intracellular water, but also differences in pharmacokinetics and pharmacodynamics (PD). ${ }^{3-5}$ It is known that sex hormones influence drug absorption, distribution, metabolism, PD, and adverse effects. ${ }^{6}$ In addition, women experience more adverse events than men, and those adverse events are more serious in women, as suggested by the US Food and Drug Administration (FDA), on the basis of its Adverse Events Reporting System. ${ }^{7}$ 
It has been hypothesized that this may be due to overdosing, differences in pharmacokinetics and PD, the fact that women are more likely to report adverse events than men, or that women take more medications than men. Actually, women use more medicines than men do and suffer more from chronic diseases, but also in general pay more attention to their health and take more care of themselves. ${ }^{7}$

Although medicines can have different effects on women and men, women still represent a small percentage in the early phases of trials $(22 \%)$, which are essential to verify drug dosage, side effects, and safety, and even when women are adequately represented in trials, study results are not presented with a sex-based approach. ${ }^{8}$ Traditionally, medical research has mostly been conducted using the male body as the basis for clinical studies. The findings of these studies have often been applied across the sexes, and health care providers have assumed a uniform approach in treating both male and female patients. ${ }^{8}$ On the other hand, it is quite evident that the female body is very different and much more complex, considering hormonal changes, menstrual period, and menopause.

More recently, medical research has started to understand the importance of taking sex into account, as symptoms and responses to medical treatment may be very different between males and females. In the mid-1980s in the US, some researchers began to study the impact of sex differences on the way diseases occur, develop, and are treated; a new medical approach was established that related the health and risk of disease with different biology, and also social, cultural, and economic roles determined by "gender". ${ }^{9}$ Until that time, the medicine was built on the paradigm of "young, adult, male, white", which conditioned not only the diagnosis and treatment of diseases, but also the testing of new drugs. In 1994, the FDA created the Office of Women's Health (FDA-OWH) to provide leadership and policy direction for the agency regarding specific issues of women's health. Within its first year, the FDA-OWH established a science program, promoting the development of sound policy and regulation for women's health research. In 2000, the World Health Organization included gender-medicine in the Equity Act to highlight equity as a principle to be applied, in order to reach a sex-appropriate care. Since 1998, the EU has also promoted women's participation in research projects, and today there is a sector of European research that has a specific focus on women. ${ }^{8,10-12}$ The scientific literature is also discussing the importance of taking sex effects into account when assessing the effect of pharmacological treatment. ${ }^{13}$
However, in agreement with the main international guidelines, until now the analyses provided by the pharmaceutical industry to regulatory authorities have not often presented safety and efficacy data by sex. On January 31, 2013, the Italian Drug Agency (Agenzia Italiana del Farmaco [AIFA]) invited pharmaceutical companies to process data disaggregated by sex during the submission of regulatory documentation (including the registration dossier), so as to highlight possible differences. ${ }^{14}$ The agency believes that this will allow more in-depth knowledge on new treatments, with the aim of offering better and safer drug therapies to all patients. Well before AIFA invitation, Novartis Farma, Italy started the first study specifically focused on gendermedicine, which also took into account the estrogenic status of patients (GENDER ATTENTION study). ${ }^{15,16}$ Novartis has implemented a gender-medicine project called MetaGeM, which includes nine observational studies sponsored by Novartis Farma Italy in a range of different clinical areas, including immune-mediated disorders such as psoriasis and psoriatic arthritis, liver and kidney transplants, infectious diseases, and the central nervous system (CNS) with Parkinson's and Alzheimer's diseases. The MetaGeM project aims to analyze and describe clinical outcomes, therapeutic approaches, and safety, by sex, by means of post hoc analyses and meta-analyses of nine observational studies performed between 2002 and 2013 in Italy. The MetaGeM project has the objective of testing whether sex differences exist in clinical outcomes, therapeutic approach, and safety parameters in the aforementioned studies. The present short paper describes the methodology of the MetaGeM project.

\section{Patients and methods}

\section{Patient population}

Selected areas of interest in the MetaGeM project and relevant studies are listed in Table 1, together with the number of evaluable patients (ie, analyzed patients). For each area of interest, one or more statistical analysis will be planned.

The Synergy study prospectively evaluated patients with psoriatic arthritis diagnosed within 8 years from enrolment baseline and treated from at least 3 months with cyclosporine as monotherapy or in combination with one or more systemic drugs. The study objectives were to assess seropositivity for former viral infection and acute viral seropositivity, and efficacy of cyclosporine alone or in combination with other immunosuppressants over 12 months. ${ }^{17}$

PSYCHAE was a multicenter observational study, aimed at defining the prevalence and incidence of psychopathological distress in psoriasis patients and at identifying the 
Table I Areas of interest of the MetaGeM project and reference observational studies

\begin{tabular}{|c|c|c|c|c|}
\hline \multirow[t]{2}{*}{ Area } & \multirow[t]{2}{*}{ Reference studies } & \multicolumn{3}{|c|}{ Evaluable patients, $n$} \\
\hline & & Total & Male & Female \\
\hline Dermatology & PSYCHAE ${ }^{18,19}$ & 786 & 477 & 309 \\
\hline (psoriasis) & GENDER ATTENTION 15,16 & 889 & 371 & 518 \\
\hline Central & DEEP $^{23}$ & 617 & 381 & 236 \\
\hline nervous & EVOLUTION ${ }^{24}$ & 635 & 256 & 379 \\
\hline system & $\mathrm{AXEPT}^{25}$ & 855 & 311 & 544 \\
\hline $\begin{array}{l}\text { Infectious } \\
\text { diseases }\end{array}$ & ICEBERG & 895 & 518 & 377 \\
\hline $\begin{array}{l}\text { Rheumatology } \\
\text { (psoriatic } \\
\text { arthritis) }\end{array}$ & Synergy ${ }^{17}$ & 225 & 121 & 104 \\
\hline Transplantation & SURF & 1,002 & 760 & 242 \\
\hline & CETRA $^{21}$ & 857 & 548 & 309 \\
\hline Safety & $\begin{array}{l}\text { DEEP, }{ }^{23} \text { EVOLUTION, }{ }^{24} \\
\text { AXEPT, }{ }^{25} \text { CETRA, }{ }^{21} \\
\text { ICEBERG, PSYCHAE, }{ }^{18,19} \\
\text { GENDER ATTENTION, }{ }^{15,16} \\
\text { Synergy }{ }^{17}\end{array}$ & & & \\
\hline
\end{tabular}

strategies employed by Italian dermatologists to manage such patients. ${ }^{18,19}$

GENDER ATTENTION was designed with the objective of exploring possible differences in the rate of adverse effects between male and female psoriatic patients treated with cyclosporine. ${ }^{15,16}$ Adverse events were defined as any untoward medical occurrence in a patient or clinical investigation subject administered a pharmaceutical product, and which did not necessarily have to have a causal relationship with this treatment. ${ }^{20}$

ICEBERG was a multicenter cross-sectional and longitudinal study of 3 years duration, aimed at assessing the prevalence (cross-sectional phase) and the incidence (longitudinal phase) of liver disease in asymptomatic carriers of the Hepatitis B surface antigen (HBsAg) not undergoing treatment.

Two studies were conducted in transplanted patients:

- SURF, consisting of a cross-sectional and a longitudinal phase; evaluated in liver-transplant recipients the proportion of renal impairment at baseline, and at 12 months since baseline, as assessed by estimated glomerular filtration rate $<60 \mathrm{~mL} / \mathrm{min} / 1.73 \mathrm{~m}^{2}$.

- CETRA, consisting of a cross-sectional and of a longitudinal phase; assessed the prevalence and evolution of gastroenteric symptoms in renal transplant recipients. ${ }^{21}$

In the DEEP study, the prevalence of "wearing off" was assessed by the Wearing Off Questionnaire-19 in Parkinson's disease patients without dementia undergoing treatment with levodopa or dopamine agonists for at least 1 year. ${ }^{22,23}$
The EVOLUTION study was conducted in patients with mild-to-moderate Alzheimer's disease treated with cholinesterase inhibitors, with the aim of evaluating their behavioral symptoms by the Manchester and Oxford Universities Scale for the Psychopathological Assessment of Dementia and the Neuropsychiatric Inventory, over at least 9 months. ${ }^{24}$

The AXEPT study was also conducted in Alzheimer's patients, with the objective of describing patients' compliance and caregivers' satisfaction with two different formulations oral versus patch - of cholinesterase inhibitors or memantine in monotherapy. ${ }^{25}$

In all the aforementioned studies, the patients were assigned to male and female groups based on information provided by the clinicians who filled in the sex field (choosing between male and female) on the case-report forms. This evaluation was based on routine clinical practice, and no further endocrinological or genetic assessment was performed.

\section{Statistical analysis}

A two-step analysis approach will be adopted:

1. A post-hoc subgroup analysis will be performed, in which the groups of male and female patients will be compared.

2. Furthermore, when more than one observational study refers to the same clinical area (ie, CNS, drug safety, and transplantation), data of interest from the different studies will be combined and analyzed according to the meta-analysis methodology. In this context, safety analyses will be also performed on pooled data from the DEEP, EVOLUTION, AXEPT, CETRA, ICEBERG, PSYCHAE, GENDER ATTENTION, and Synergy studies.

Meta-analyses refer to methods focused on contrasting and combining results from different studies in the hope of identifying patterns among study results, sources of disagreement among those results, or other interesting relations that may come to light in the context of multiple studies. ${ }^{26}$ In order to meta-analyze individual participant data (IPD) appropriately, a model will be applied that directly synthesizes the IPD in a one-step approach while accounting for the clustering of participants within studies. ${ }^{27}$ The meta-analysis of IPD is an increasingly popular alternative to traditional methods for meta-analysis, which usually synthesize aggregate studylevel data obtained from study publications or study authors. ${ }^{28}$ Meta-analysis of IPD has many potential advantages, both statistically and clinically, over meta-analysis of aggregate data. Aggregate data are often not available, poorly reported, 
derived and presented differently across studies, and more likely to be reported (and in greater detail) when statistically or clinically significant, amplifying the threat of publication bias and within-study selective reporting.

On the contrary, having IPD facilitates standardization of analyses across studies and direct derivation of the information desired, independently of significance or how it was reported. IPD may also have a longer follow-up time, more participants, and more outcomes than were considered in the original study publication. This means that IPD meta-analyses are potentially more reliable than aggregatedata ones, and the two approaches may lead to different conclusions. ${ }^{29-32}$

However, meta-analysis of IPD is not without disadvantages. In particular, substantial time and costs are usually required to contact study authors, obtain IPD, input and clean the provided data, resolve any data issues through dialogue with the data providers, and generate a consistent data format across studies. IPD meta-analyses usually have the same objectives as the original studies, for which ethical approval should exist. Data analyzed in the MetaGeM project come from studies sponsored by the same company, which have already undergone data cleaning and standard data formatting; ethical approval was already obtained for all studies. Disadvantages of meta-analysis of IPD previously described relate to data availability or ethical concerns, and are therefore overcome in the MetaGeM project.

With regard to MetaGeM, all analyses will be performed by a designated Contract Research Organization (CRO) MediData Italy. Quantitative variables will be described by mean, standard deviation, median, first and third quartiles, minimum, and maximum, and qualitative ones by absolute and relative frequency. All evaluable patients will be included in the statistical analysis. The patients evaluable for the analyses will be defined according to each statistical analysis plan.

Patients with missing values will not be excluded from the analysis, nor will their data be replaced; frequency of missing data will be given for all analyzed variables. In more detail, descriptive analysis by sex will be performed regarding:

- study-specific disease-related outcomes (eg, disease severity, anamnesis)

- primary outcome(s) of the study

- therapies: prescribed/administered

- standardized scales where applicable

- adverse events.

The male and female patient populations will be compared by statistical tests. Comparisons will be performed by Student's $t$-test, $\chi^{2}$ test, or Fisher's exact test if appropriate. The accepted level of significance has been set at $\alpha=0.05$. As post hoc analyses, all $P$-values presented will be exploratory.

\section{Discussion}

It is increasingly accepted that scientific research should increase the female presence in clinical trials in order to be equal and correct, and all the key stakeholders should be involved in this process. ${ }^{33}$ The aim is to have a medicine not only illness-focused but also patient-focused: a medicine able to take into consideration all the patient characteristics and so to produce a personalized therapy. ${ }^{8}$ The fact that women represent a small percentage of patients in clinical trials can be influenced by several factors, including ethical considerations: women have less time available due to their dual job (mothers and professionals) to fulfill trial requirements (visits, tests, etc), and there is a potential risk of damaging the fetus in fertile women enrolled in a trial. Furthermore, the female body is complex, considering hormonal changes, menstrual periods, the use of birth-control pills, and menopause. For all those reasons, in order to have similar results in a group of men and women, it is necessary to recruit a bigger sample. Last but not least, women's participation in research studies has higher insurance and organizational costs.

An American study has demonstrated that most cardiovascular clinical trials published in the most famous journals have not presented results distinguished by sex, although there was a clear example of this kind of information in trials financed by the National Institutes of Health. ${ }^{8}$ Several clinical studies have pointed out the value of sex in predicting drug response, eg, males are more likely to respond to digoxin or to biological disease-modifying rheumatic drugs. ${ }^{33-35}$ Sex-specific medicine is crucial to understand how different therapeutic needs are in men and women, and consequently to define potential different therapeutic approaches between males and females. ${ }^{36}$

Clinical research sponsored by Novartis Farma Italy in the last decade has included several large observational studies in important medical areas, such as dermatology, ${ }^{15,16,18,19}$ rheumatology, ${ }^{17}$ the $\mathrm{CNS},{ }^{22-25}$ and infectious diseases, ${ }^{37}$ but none of those studies, except the aforementioned GENDER ATTENTION study, adopted a sex-specific approach in data analysis. Based on the increasing interest in gender-medicine and moved by the great amount of clinical data available through those large national studies, we decided to reanalyze these data from a gender perspective. Some of the studies considered are recent enough (eg, GENDER ATTENTION started enrollment in 2011, SURF in 2012), but others are rather old (PSYCHAE started in 2002, CETRA in 2006), and we are aware that this 
is a limitation of our project, since it means that some of the therapeutic strategies analyzed may be obsolete. However, due to the great amount of available data, we think that it is worth it to reanalyze this large database anyway, at least to explore preliminarily the sex-specific therapeutic approach and safety data in the considered diseases.

From the methodology point of view, we first adopted the post hoc subgroup analysis for different clinical areas: PSYCHAE and GENDER ATTENTION in psoriasis, ICEBERG in infectious diseases, Synergy in active psoriatic arthritis, DEEP, EVOLUTION, and AXEPT in CNS disorders, and SURF and CETRA in liver and kidney transplantation. The subgroup analysis is often chosen by practitioners and regulatory agencies to know whether there are subgroups of trial participants who are more (or less) likely to be helped (or harmed) by the intervention under investigation. Sometimes, this can drive changes in practice guidelines, but meaningful information from subgroup analyses within a randomized trial can be restricted by multiplicity of testing and low statistical power. However, in the case of groups not defined a priori, this kind of analysis provides useful exploratory findings whose validity has to be discussed in the light of current scientific knowledge and findings from similar studies. ${ }^{38}$ In order to reconcile the wish to find genuine differences between subgroups while minimizing the risk of accepting false positives, it has to be accepted that the results of subgroup analysis may only generate hypotheses.

A further possibility is to perform a meta-analysis of data from different studies, the method we adopted for the areas in our project where more than an observational study was present: CNS with DEEP, EVOLUTION, and AXEPT, transplantation with SURF and CETRA, and safety analyses on the pooled data of the studies.

In conclusion, with the limitations of retrospective unpredefined analyses and of considering clinical data that is not always up to date, the MetaGeM project may lead to some useful considerations on possible sex differences in a large spectrum of therapeutic approaches, clinical response, or safety of some diseases, in order to design more appropriately, further clinical trials from a sex-specific perspective.

\section{Acknowledgments}

The study was supported by an unrestricted educational grant from Novartis Farma SpA, Origgio (VA), Italy. The authors meet criteria for authorship as recommended by the International Committee of Medical Journal Editors (ICMJE), and were fully responsible for all aspects of manuscript development. We are grateful to MediData
(Modena, Italy) for data collection and statistical analysis and to Renata Perego for help in writing the manuscript.

\section{Disclosure}

DC is a part time employee of Novartis Farma and has received grants from Allergan and Aventis; GB, DV and EZ are employees of Novartis Farma; SS and SR are employees of MediData. The authors report no further conflicts of interest in this work.

\section{References}

1. Woosley RL, Antony M, Peck CC. Exploring the biological contributions to human health: does sex matter? J Womens Health Gend Based Med. 2001;10(5):433-439.

2. Baggio G, Corsini A, Floreani A, Giannini S, Zagonel V. Gender medicine: a task for the third millennium. Clin Chem Lab Med. 2013;51(4):713-727.

3. Koren G, Nordeng H, MacLeod S. Gender differences in drug bioequivalence: time to rethink practices. Clin Pharmacol Ther. 2013;93(3):260-262.

4. Ueno K, Sato H. Sex-related differences in pharmacokinetics and pharmacodynamics of anti-hypertensive drugs. Hypertens Res. 2012;35(3):245-250.

5. Soldin OP, Mattison DR. Sex differences in pharmacokinetics and pharmacodynamics. Clin Pharmacokinet. 2009;48(3):143-157.

6. Spoletini I, Vitale C, Malorni W, Rosano GM. Sex differences in drug effects: interaction with sex hormones in adult life. Handb Exp Pharmacol. 2012;(214):91-105.

7. Miller MA. Gender-based differences in the toxicity of pharmaceuticals - the Food and Drug Administration's perspective. Int J Toxicol. 2001;20(3):149-152.

8. Cassese M, Zuber V. Clinical trials and gender medicine. Ann Ist Super Sanita. 2011;47(1):100-103.

9. Regitz-Zagrosek V, Seeland U. Sex and gender differences in clinical medicine. Handb Exp Pharmacol. 2012;(214):3-22.

10. Obias-Manno D, Scott PE, Kaczmarczyk J, et al. The Food and Drug Administration Office of Women's Health: Impact of science on regulatory policy. $J$ Womens Health. 2007;16(6):807-815.

11. Merkatz RB, Temple R, Sobel S. Women in clinical trials of new drugs. A change in Food and Drug Administration policy. $N$ Engl $J$ Med. 1993;329(4):292-296.

12. [No authors listed]. Agenda for Research on Women's Health for the 21st Century: A Report of the Task Force on the NIH Women's Health Research Agenda for the 21st Century. California: University of California Libraries; 1999.

13. [No authors listed]. Putting gender on the agenda. Nature. 2010; 465(7299):665.

14. AIFA. Farmaci e genere - avviso alle aziende farmaceutiche. 2013. Available from: http://www.agenziafarmaco.gov.it/it/content/farmacie-genere. Accessed August 8, 2014.

15. Colombo D, Bellia G. Il paziente psoriasico e l'attenzione alle differenze di genere: lo studio GENDER ATTENTION. G Ital Dermatol Venereol. 2013;148 Suppl 1:21.

16. Colombo D, Graziottin A, Bellia G, Vena GA, Banfi G, Cassano N. Influence of sex on incidence of side effects in plaque psoriasis patients treated with cyclosporine. Preliminary results from the Italian observational GENDER ATTENTION study. J Am Acad Dermatol. 2014; 70 Suppl 1:AB173.

17. Colombo D, Chimenti S, Grossi P, et al. Prevalence of past and reactivated viral infections and efficacy of cyclosporine A as monotherapy or in combination in patients with psoriatic arthritis - Synergy study: a longitudinal observational study. Biomed Res Int. 2014;2014: 941767. 
18. Finzi A, Colombo D, Caputo A, et al. Psychological distress and coping strategies in patients with psoriasis: the PSYCHAE Study. J Eur Acad Dermatol Venereol. 2007;21(9):1161-1169.

19. Colombo D, Caputo A, Finzi A, et al. Evolution of and risk factors for psychological distress in patients with psoriasis: the PSYCHAE study. Int J Immunopathol Pharmacol. 2010;23(1):297-306.

20. International Conference on Harmonisation of Technical Requirements for Registration of Pharmaceuticals for Human Use. ICH Harmonised Tripartite Guideline - Post-approval Safety Data Management: Definitions and Standards for Expedited Reporting E2D. Geneva: ICH Secretariat; 2003.

21. Ponticelli C, Colombo D, Novara M, Basilisco G. Gastrointestinal symptoms impair quality of life in Italian renal transplant recipients but are under-recognized by physicians. Transpl Int. 2010;23(11): 1126-1134.

22. Abbruzzese G, Antonini A, Barone P, et al. Linguistic, psychometric validation and diagnostic ability assessment of an Italian version of a 19-item wearing-off questionnaire for wearing-off detection in Parkinson's disease. Neurol Sci. 2012;33(6):1319-1327.

23. Stocchi F, Antonini A, Barone P, et al. Early detection of wearing off in Parkinson disease: the DEEP study. Parkinsonism Relat Disord. 2014;20(2):204-211.

24. Spalletta G, Caltagirone C, Padovani A, et al. Cognitive and affective changes in mild to moderate Alzheimer's disease patients undergoing switch of cholinesterase inhibitors: a 6-month observational study. PLoS One. 2014;9(2):e89216.

25. Bernabei R, Rossini PM, Di Cioccio L, et al. Compliance and caregiver satisfaction in Alzheimer's disease: results from the AXEPT study. Dement Geriatr Cogn Dis Extra. 2012;2(1):418-432.

26. Greenland S, O’Rourke K. Meta-analysis. In: Rothman KJ, Greenland S, Lash T, editors. Modern Epidemiology. 3rd ed. Philadelphia: Lippincott Williams and Wilkins; 2008:652.

27. Jones AP, Riley RD, Williamson PR, Whitehead A. Meta-analysis of individual patient data versus aggregate data from longitudinal clinical trials. Clin Trials. 2009;6(1):16-27.
28. Stewart LA, Parmar MK. Meta-analysis of the literature or of individual patient data: is there a difference? Lancet. 1993;341(8842):418-422.

29. Riley RD, Lambert PC, Staessen JA, et al. Meta-analysis of continuous outcomes combining individual patient data and aggregate data. Stat Med. 2008;27(11):1870-1893.

30. McCormack K, Grant A, Scott N. Value of updating a systematic review in surgery using individual patient data. Br J Surg. 2004;91(4): 495-499.

31. Jeng GT, Scott JR, Burmeister LF. A comparison of meta-analytic results using literature vs individual patient data. Paternal cell immunization for recurrent miscarriage. JAMA. 1995;274(10):830-836.

32. Berlin JA, Santanna J, Schmid CH, Szczech LA, Feldman HI. Individual patient- versus group-level data meta-regressions for the investigation of treatment effect modifiers: ecological bias rears its ugly head. Stat Med. 2002;21(3):371-387.

33. Woosley RL, Anthony M, Peck CC. Biological sex analysis in clinical research. J Womens Health Gend Based Med. 2000;9(9):933-934.

34. Rathore SS, Wang Y, Krumholz HM. Sex-based differences in the effect of digoxin for the treatment of heart failure. NEngl J Med. 2002; 347(18):1403-1411.

35. Kleinert S, Tony HP, Krause A, et al. Impact of patient and disease characteristics on therapeutic success during adalimumab treatment of patients with rheumatoid arthritis: data from a German noninterventional observational study. Rheumatol Int. 2011;32(9):2759-2767.

36. Daïen CI, Morel J. Predictive factors of response to biological disease modifying antirheumatic drugs: towards personalized medicine. Mediators Inflamm. 2014;2014:386148

37. Utili R, Cogo A, Cristini F, et al. Clinical experience with daptomycin in Italy: results from a registry study of the treatment of Gram-positive infections between 2006 and 2009. J Chemother. 2012;24(2): 113-121.

38. Cook DI, Gebski VJ, Keech AC. Subgroup analysis in clinical trials. Med J Aust. 2004;180(6):289-291.
Open Access Journal of Clinical Trials

\section{Publish your work in this journal}

The Open Access Journal of Clinical Trials is an international, peerreviewed, open access journal publishing original research, reports, editorials, reviews and commentaries on all aspects of clinical trial design, management, legal, ethical and regulatory issues, case record form design, data collection, quality assurance and data auditing

\section{Dovepress}

methodologies. The manuscript management system is completely online and includes a very quick and fair peer-review system, which is all easy to use. Visit http://www.dovepress.com/testimonials.php to read real quotes from published authors. 